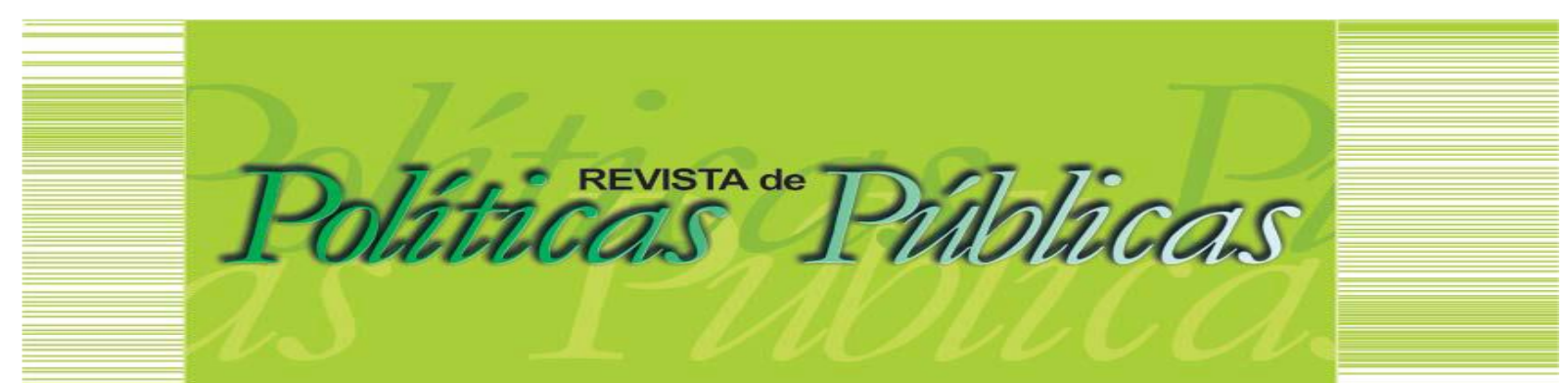

\title{
O ENSINO DA LÍNGUA NHEENGATU EM ALDEIAS URBANAS DE MANAUS ${ }^{1}$
}

\author{
Hellen Cristina Picanço Simas² \\ Amanda Ramos Mustafa ${ }^{3}$ \\ Ytanajé Coelho Cardoso 4
}

\section{Resumo}

O objetivo deste artigo é discutir a maneira como se desenvolve o ensino e aprendizagem da língua nheengatu no Centro Municipal de Educação Escolar Indígena UkaUmbuesaraWakenaiAnumarehit (CemeeiWakenai), localizado na comunidade indígena Parque das Tribos, na cidade de Manaus. Para tanto, utiliza o método de pesquisa de campo, amparado pela técnica da entrevista semiestruturada. Os resultados apontam que o ensino no CemeeiWakenai se desenvolve em contexto multiétnico, com alunos de diversas etnias. Conclui que as práticas linguísticas em nheengatu representam para esses estudantes, indígenas citadinos, a sua reafirmação identitária e uma ferramenta de luta pelos seus direitos.

Palavras-chave: Ensino e aprendizagem. Nheengatu. Parque das Tribos. Reafirmaçãoidentitária.

\section{TEACHING THE NHEENGATU LANGUAGE IN MANAUS URBAN VILLAGES}

\section{Abstract}

The aim of this article is to discuss how to teach and learn the Nheengatu language develops at the Municipal Center for Indigenous School Education UkaUmbuesaraWakenaiAnumarehit (CemeeiWakenai), located in the indigenous community Parque das Tribos, in the city of Manaus. The field research method was used, supported by the semi-structured interview technique. The results demonstrate that teaching at CemeeiWakenai takes place in a multiethnic context, with students of different ethnicities. It concludes that the linguistic practices in nheengatu represent for these students, indigenous city residents, their affirmation of identity and a tool for the fight for their rights.

Keywords: Teaching and learning. Nheengatu. Parque das Tribos. Identity reafirmation

Artigo recebido em: 06/10/2020 Aprovado em: 27/05/2021 DOI: http://dx.doi.org/10.18764/2178-2865.v25n1p396-413

\footnotetext{
1 presente trabalho foi realizado com apoio da Coordenação de Aperfeiçoamento de Pessoal de Nível Superior - Brasil (CAPES) - Código de Financiamento 001

2 Linguista. Doutora em Linguística pela Universidade Federal da Paraíba (UFPB). Professora da Universidade Federal do Amazonas. Programa de Pós-Graduação em Educação (PPGE) e Coordenação de Aperfeiçoamento de Pessoal de Nível Superior. E-mail: hellenpicanco@ufam.edu.br

3 Mestre em Educação pela Universidade do Estado do Amazonas (UEA). Professora de Língua Inglesa da Secretaria de Estado de Educação e Desporto (SEDUC/AM). E-mail: mustafa.amanda@gmail.com

${ }^{4}$ Mestre em Letras e Artes (2015-2017), pela Universidade do Estado do Amazonas (UEA). Professor de Língua Portuguesa da Secretaria de Estado de Educação e Desporto (SEDUC/AM) e professor colaborador no Parfor/UEA, bolsista da Fundação de Amparo à Pesquisa do Amazonas. E-mail: ytanajecardoso@gmail.com.
} 


\section{INTRODUÇÃO}

Os indígenas representam uma população cada vez mais presente nas cidades do Brasil, particularmente nas cidades amazônicas. Mas, ao deixarem seus locais de origem e migrarem para os centros urbanos, acabam se defrontando com situações de exclusão, marginalização e descaso para com seus direitos e suas tradições culturais. Essa realidade vem exigindo ações capazes de criar condições para que esses indivíduos possam preservar seus saberes, práticas e realidades multilíngues, assim como também seus projetos futuros.

Em 2015, a Coordenação dos Povos Indígenas de Manaus e Entorno (COPIME) identificou que cerca de 34 etnias indígenas residem em 51 bairros da cidade de Manaus, sendo elas: Munduruku, Tikuna,Sateré-Mawé, Desana, Tukano, Miranha, Kaixana, Baré, Kokama, Apurinã, Tuyuka, Piratapuya, Kamaiurá, Kambeba, Mura,Maraguá, Baniwa,Macuxi, Wanano, Tariano, Bará, Arara [do Aripuanã], Karapanã, Barasana, Anambé, Deni, Kanamari, Katukina, Kubeo,Kulina, Marubo, Paumari, Arara do Pará e Manchineri, convivendo com os velhos paradigmas de discriminação e exclusão social. Vivem em comunidades, ora em convívio com outras etnias, ora não. Contam com a mobilização umas das outras e com apoio de organizações políticas e civis, na luta para terem seus direitos reconhecidos ante a sociedade não indígena. Boa parte das comunidades indígenas citadinas aprendem a se organizar, a construir redes de relações interétnicas que thes possibilitam sobreviver nos novos contextos sociais. Convivem com os não indígenas, mesclando seus costumes aos da vida urbana, sem, contudo, anular suas origens. Uma vez organizadas em associações e cooperativas, se articulam politicamente para reivindicarem seus direitos, dentre os quais o fortalecimento de suas línguas.Isso implica dizer que estes sujeitos empregam extremo esforço para manter viva a língua e suas raízes culturais, em face de todo o hibridismo que os envolve.

É nesse panorama de diversidade e de trocas culturais que se insere o Parque das Tribos, uma comunidade indígena multiétnica, localizada no bairro Tarumã, Zona Oeste de Manaus, oficialmente fundada em 18 de abril de 2014, com o assentamento de 280 famílias. Em 2018, o Parque das Tribos contava com 26 etnias (MUSTAFA, 2018): Apurinã, Baniwa, Barassana, Baré, Dessana, Hixcariano, Kanamari, Kambeba, Karapanã, Kokama, Kulina, Kuripako, Marubo, Miranha, Munduruku, Mura, Piratapuia, Sateré-Mawé, Tariano, Tikuna, Tukano, Tuyuka, Wanano, Hupda, Bara e Tapuio.Neste espaço, os indígenas diligenciam sua organização interna gerida pela coordenação de líderes que estabelecem planos de ação referentes à legalização do território por eles habitado, a melhores condições de saneamento básico, de saúde, de educação e afins. No cerne das preocupações, destaca-se o Centro Municipal de Educação Escolar Indígena Uka Umbuesara Wakenai 


\section{O ENSINO DA LÍNGUA NHEENGATU EM ALDEIAS URBANAS DE MANAUS}

Anumarehit, que significa, em nheengatu, "espaço de aprender a origem dos guerreiros", visto como forte instrumento de voz e de visibilidade da comunidade na sociedade não indígena.

Sob essa perspectiva, o objetivo do presente estudo é discutir o ensino da língua nheengatu no Cemeei Wakenai a fim de verificar a forma como se desenvolve o ensino da língua referida neste centro etnoeducacional. Para tanto, buscou-se destacar a didática e a proposta pedagógica utilizada neste Cemeei; destacar as dificuldades e as conquistas no dia a dia deste projeto etnolinguísitco e, por fim, evidenciar o que o aprendizado da língua nheengatu tem representado para a nova geração de indígenas citadinos no Parque das Tribos.

A fundamentação teórica está pautada em trabalhos que discutem a presença indígena na cidade,dos quais citam-se Sastre (2015) e Maher (2016); outros que tratam da língua como elemento indissociável aos processos de afirmação identitária dentro de uma comunidade de fala, dentre os quais destacam-se Athias (2008), Rajagopalan (1998)e ainda pesquisadores como Baniwa (2019),Fernandes (2018), Mustafa (2018) e Simas (2012), autores que discorrem sobre a educação escolar indígena como forma de validar as identidades étnicas, exercida de modo comunitário, intercultural, bilíngue/multilíngue, específica e diferenciada no cenário da Educação Escolar Indígena, respeitando o pluralismo cultural.

Metodologicamente, este trabalho foi embasado na abordagem qualitativa, a qual é definida por Minayo (2013) e Triviños (2013) como um estudo voltado para avaliação de dados não mensuráveis, com foco em sentimentos, sensações, percepções, pensamentos, intenções e comportamentos de um indivíduo ou grupo de pessoas. Como procedimento, realizou-se, além de pesquisa bibliográfica, uma pesquisa de campo no Centro Municipal de Educação Escolar Indígena Uka Umbuesara Wakenai Anumarehit (Cemeei Wakenai), na comunidade indígena Parque das Tribos.

Os dados foram coletados por meio de observação participante e de entrevista semiestruturada junto a uma docente do referido Cemeei, entre os meses de outubro de 2017 a fevereiro de 2018, totalizando 12 visitas, cujos achados foram registrados em diário de campo. A outra etapa da pesquisa foi a transcrição dos registros para análise e, por fim, as discussões do que fora percebido ante o fenômeno do ensino-aprendizagem da língua nheengatu na perspectiva da educação escolar indígena no centro educacional em estudo.

A relevância da temática elucidada ocorre pelo fato de a comunidade indígena Parque das Tribos apresentar contexto multiétnico ímpar na cidade de Manaus, ou seja, várias etnias convivem no mesmo território citadino. Neste cenário, o Cemeei Wakenai se sobressai na reafirmação da identidade e das tradições indígenas por meio de um hibridismo cultural e linguístico norteado pelo sentimento de pertencimento coletivo construído pelos povos que ali residem. 
As sessões a seguir discorrem sobre a presença de indígenas em contexto urbano e suas lutas por reconhecimento étnico, respeito identitário e melhores condições de sobrevivência e o papel da língua indígena nesse processo. Neste aspecto, aborda-se o esforço que empregam para que a língua e cultura sejam transmitidas às suas posteridades. Para tanto, apresenta sucintamente como a Educação Escolar Indígena se desenvolve na cidade de Manaus, descrevendo as parcerias feitas entre as aldeias urbanas e a Secretaria Municipal de Educação do Município de Manaus (Semed). Posteriormente, têm-se a apresentação dos resultados, os quais discutem toda a dinâmica de ensino e aprendizagem do Cemeei Wakenai com foco nos objetivos propostos.

\section{INDÍGENAS EM CENTROS URBANOS: a luta pela reafirmação da identidade}

Não é de hoje que as cidades brasileiras recebem, cada vez mais, migrantes indígenas, que buscam os grandes centros para terem acesso a alguns recursos que não têm nas aldeias: oportunidades de estudo e melhores condições econômicas. Trata-se, porém, de uma migração que gera muitos desafios para esta população, como a falta de moradia, de educação escolar bilíngue para os jovens, de segurança, de estabilidade financeira, preconceitos, dentre outros.

$\mathrm{Na}$ narrativa de Sastre (2015), as migrações indígenas para as grandes cidades vêm ocorrendo desde meados do século XX, precisamente a partir das décadas de 1950 e 1970, quando uma onda de mão de obra chega às metrópoles. Desse modo, pode-se considerar que as razões da migração não foram só econômicas, mas também educacionais e de saúde, além dos que se viram obrigados ao deslocamento porque tiveram seus territórios invadidos. Ao transferir a situação para a região Norte, lembra Pereira (2016) que a Floresta Amazônica há muito deixou de ser o lar de milhares de indígenas. As causas disso, explica o autor,vai da escassez de alimentos ao avanço das cidades sobre as matas. Em Manaus, conforme citado anteriormente, os indígenas podem ser encontrados em todas as regiões da cidade. Embora a COPIME - como já assinalado - tenha contabilizado34 etnias alocadas em 51 bairros da cidade, ainda não há dados precisos e oficiais de quantas etnias ou línguas faladas existam na metrópole, a não ser o do censo de 2010,do Instituto Brasileiro de Geografia e Estatística - IBGE, que apontou 4.020 indígenas autodeclarados, representando 92 etnias, que falam 36 línguas, distribuídos em 62 bairros (PEREIRA, 2016).

O fato é que esse contato gerou profundas mudanças sociais, culturais, identitárias e linguísticas na vida desses povos. Ao refletir a respeito das transformações e o perigo de perda cultural e crises identitárias por parte desses novos moradores urbanos, Cohn (2001, p. 36) tece o seguinte comentário: 
Muito se comenta, e se lamenta, que os índios estão perdendo sua cultura. Um índio calçado e vestido com calça jeans, falando português, utilizando gravadores e vídeos ou morando em uma favela [...] aparece aos olhos do público como menos índio. Eles deveriam seguir suas tradições, se diz. E nós deveríamos deixá-los em paz, devolvê- -los ao isolamento, para que possam seguir seus caminhos.

Como se vê, a presença do indígena nos centros urbanos, embora não seja recente, é complexa e insere-se cada vez mais em discussões, especificamente por conta de suas condições de sobrevivência, reafirmação de sua identidade cultural, linguística e de suas formas de resistência às percepções discriminatórias e civilizatórias que os veemcomo alguém fora do seu lugar, um sujeito que perdeu sua identidade social ou cultural.

A cidade de Manaus pode ser apontada como exemplo dessas condições. Nela concentram-se diferentes grupos étnicos, que se deslocaram para a capital. Todavia, a maioria vive em estado de exclusão pela sociedade não indígena, presenciando a negação de seus direitos e até preconceito em relação à identidade étnica por não viverem mais em aldeias e assimilarem os valores culturais concernentes à língua e ao modo de vida dos não indígenas. Um dos principais fatores que se encontra na raiz da invisibilidade e da desconfiança com relação ao indígena que vive na cidade centra-se no fato de os povos indígenas serem, equivocadamente, colocados como prisioneiros de suas ancestralidades também em termos de territorialidade, ou seja, esses indivíduos são comumente vistos como pertencentes exclusivamente à floresta, isto é, "não há [...] espaço no imaginário nacional para índios 'legítimos' em avenidas, shoppings, universidades - esses seriam espaços exclusivamente de 'brancos', de não índios", conforme assinala Maher (2016, p. 62).

O fato é que as interações entre indígenas e não indígenas, em grande parte, são sinalizadas como relações de atritos, deixando claro o sentido desigual do contato, que se formata como uma força que destrói, gerando processo de mudança das comunidades indígenas, em virtude de sua situação desfavorável, como, por exemplo, a perda da língua nativa. Segundo Brostolin (2003), a perda de uma língua indígena é inquietante, porque muitas vezes, ocorre muito rapidamente, em um espaço de três gerações, acontecendo quando uma comunidade antes monolíngüe em língua indígena, se torna bilingue (português/língua indígena) e depois retorna a condições de monolíngüe, porém em língua portuguesa.

\section{A LÍNGUA COMO ELEMENTO DE CONSTRUÇÃO DA IDENTIDADE CULTURAL DOS POVOS INDÍGENAS}

Pode-se dizer que o processo de construção da identidade cultural de um indivíduo é concebido por inúmeras formas, a mais notável diz respeito à língua, na qual se reflete o contorno 
subjetivo e histórico do ser humano desde a sua mais tenra infância. Destarte, o falante, imbuído num conjunto complexo e multiforme delineado pelos fatores biológicos, cognitivos, sociais e culturais é o responsável por materializar o código linguístico em uma sociedade,pois,como afirma Calvet (2002, p.12), "as línguas não existem sem as pessoas que as falam, e a história de uma língua é a história de seus falantes".Assim, a língua é contemplada como um elemento chave indissociável da raiz identitária de um grupo. Por ser interativa, consegue expressar e transmitir latentemente a cultura e os saberes tradicionais de um povo,portanto, é um importante traço cultural.

Nesse sentido, reconhecer a importância da língua na identidade cultural indígena significa, antes de tudo, compreender as situações e conceitos que perpassam a nomenclatura identidade voltada ao cenário étnico. Athias (2008, p.40) define identidade étnica como um "sentimento de pertencimento de um determinado grupo social, apoiando-se numa crença de origem comum e na construção de um repertório de elementos diacríticos. Isso permite a comunidade étnica se definir, se organizar e se diferenciar diante dos outros".

Logo, o conceito apresentado por Athias (2008), quando aplicado no interior de um grupo indígena, busca estabelecer uma conexão entre identidade étnica e continuidade da língua,uma vez que esta também apresenta essas mesmas características da definição supracitada dentro do processo de identidade coletiva; isso implica dizer que ambas estão imbricadas em uma via de mão dupla, na medida em que são manifestas e compartilhadas mutuamente.Rajagopalan (1998) salienta que a construção da identidade de um indivíduo acontece por meio da língua, porque ambas(língua e identidade) encontram-se em constante processo de evolução. Ainda conforme este autor, a identidade não é algo sedimentado e muito menos estático, ao contrário, é um sistema emparelhado às transições vividas pelos falantes, sendo ainda aquilo que eles assimilam na e pela própria língua por meio das esferas sociais como a família e a escola.

Desse modo, a caracterização da identidade cultural de uma comunidade indígena por meio da sua língua exige que esta se mantenha viva, o que só é possível por meio das práxis, ou seja, com o código sendo partilhado nos mais variados contextos e sob diversas maneiras, não só como procriação simbólica, porém, contributiva e pragmática na formação da identidade de seus falantes. Todavia, isto é um dos maiores desafios enfrentados por esses povos, em especial os alocados em grandes centros urbanos, em uma época em que as mudanças ocorrem vertiginosamente de modo simultâneo e multifacetadona vigente era globalizada. Então, faz-se necessário ter ciência de que, quando uma língua deixa de ser falada ou compartilhada pelos membros de uma comunidade, vai perdendo sua faculdade reprodutiva, gerando, como última consequência, o seu desaparecimento ou glototanásia (COUTO, 2012, p. 84). 


\section{O ENSINO DA LÍNGUA NHEENGATU EM ALDEIAS URBANAS DE MANAUS}

Nesse contexto, a educação escolar pode ser uma alternativa para a superação das perdas significativas da língua, da cultura e da identidade da população indígena. O papel da educação escolar indígena é reafirmar as identidades étnicas, valorizando suas línguas e ciências e garantindo aos indígenas e às suas comunidades 0 acesso às informações, conhecimentos técnicos e científicos da sociedade nacional e das demais sociedades, seja elas indígenas ou não (BRASIL, 1998). Por isso, a seguir vamos discutir o ensino-aprendizagem na língua nheengatu no Ceemei.

4 PARQUE DAS TRIBOS: aspectos históricos e sociolinguísticos dessa significativa aldeia urbana

O Parque das Tribos, fundado na década de 1970, por indígenas da etnia Kokamaoriundos do Município de Tefé, no Estado do Amazonas, migraram para Manaus em busca de estudo e trabalho. Ao longo do tempo, foram se estabelecendo em uma área total de 14.220 ha na rua Rio Purus, 702, bairro Tarumã, zona oeste de Manaus. Atualmente é um espaço ocupado por cerca de 600 famílias, indígenas e não indígenas, que depois de muita reivindicação perante as políticas públicas, receberam instalação de água encanada, luz elétrica e asfaltamento de suas principais ruas. As habitações são formadas por madeiras emaranhadas a materiais como lonas, tabiques, PVC e tijolos. Por ter um histórico de formação indígena, bem como apresentar um quantitativo elevado de indígenas no local, os moradores lutam para que o lugar seja oficialmente reconhecido como o primeiro bairro indígena da cidade (MUSTAFA, 2018).

Em 2015, a pedido da própria comunidade, professores, acadêmicos e mestrandos do curso de Letras da Universidade do Estado do Amazonas, no ano de 2015, elaboraram um laudo linguístico para catalogar a situação das línguas étnicas presentes no Parque das Tribos. Na época, o documento apontou que existiam cerca de 24 línguas indígenas neste espaço, sendo elas: representando $11,42 \%$ das $210^{1}$ línguas indígenas encontradas no Brasil, as quais foram classificadas em três categorias de estágios, em referência à vitalidade desses idiomas sendo: 13 línguas vivas apurinã, baniwa, dessano, kokama, kanamari, kuripako, marubo, piratapuia, sateré-mawé, tikuna, tukano, tuyuka e wanano,utilizadas pelos falantes na comunicação diária, 1 língua na memória tupinambá jaguari, essa correspondente àquela que, embora o falante não a utilize, consegue lembrar parte do léxico e 10 línguas mortas - baré, barassanohixkariana, kaixana, kambeba, kulina, miranha, munduruku, mura e tariano; neste caso a língua materna já não existe, foi substituída pela língua portuguesa. Vale destacar que os dados mencionados se referem exclusivamente ao panorama linguístico encontrado na comunidade elucidada. (MUSTAFA, 2018). No início de 2020 houve um novo censo no local, realizado pelos próprios moradores, o qual demonstrou que atualmente existem cerca de 36 etnias que ainda estão sendo catalogadas. 
Nesse cenário, os moradores do Parque das Tribos buscam manter a formação de uma sociedade pluriétnica. É uma luta envolvendo questões sociais, econômicas e políticas, estando no núcleo de tudo isso, os esforços empreendidos no sentido de manter um território legítimo para habitarem dignamente. Neste sentido, a educação escolarindígena constitui,nessa aldeia urbana,um instrumento de empoderamento dos seus diversos povos, nointuito de compartilhar o conhecimento a respeito dos saberes, costumes e culturas, sempre respeitando a identidade de cada etnia e fortalecendo oslaços de solidariedade coletiva para também lutarem por melhores condições de sobrevivência na cidade.

\section{O CENTRO MUNICIPAL DE EDUCAÇÃO ESCOLAR INDÍGENA UKA UMBUESARA WAKENAI ANUMAREHIT}

O Centro Municipal de Educação Escolar Indígena Uka Umbuesara Wakenai Anumarehit significa "espaço de aprender a origem dos guerreiros"e é chamado pelos moradores da comunidade Parque das Tribos como escola ou espaço cultural indígena Wakenai. Sua criação deve-se à iniciativa da professora e pedagoga indígena Ana Cláudia Tomas, da etnia Baré, formada pelo Curso de Pedagogia Intercultural. Cláudia Baré, como é conhecida, pertence ao quadro de docentes indígenas da Secretaria Municipal de Educação de Manaus (Semed-AM).

As atividades do Cemeei Wakenai tiveram início, oficialmente, em outubro de 2014, com noventa 90 alunos e atualmente possui 70com idade entre 9 a 53 anos formados por crianças, jovens, adolescentes e adultos advindos de variadas etnias -Apurinã, Baniwa, Barassana, Baré, Dessana, Hixcariano, Kanamari, Kambeba, Karapãna, Kokama, Kulina, Kuripako, Marubo, Miranha, Munduruku, Mura, Piratapuia, Sateré-Mawé, Tariano, Tikuna, Tukano, Tuyuka, e Wanano, além de alguns alunos não indígenas, que residem na comunidade e têm interesse em aprender a língua e cultura indígena.

A língua ensinada na escola é a nheengatu, na condição de segunda língua (L2), pois a primeira, de domínio de todos, é a portuguesa (L1). A escolha do nheengatu se dá pelo fato de ser 0 idioma oficialmente mais falado entre os povos indígenas da comunidade e de domínio da professora. Esse trabalho é feito sem, contudo, desconsiderar as demais línguas presentes nesse espaço de aprender, pois há uma preocupação de que no ambiente doméstico as famílias que têm domínio de suas línguas étnicas permaneçam se comunicando em seus idiomas de origem, com a intenção de manter viva a tradição da prática linguística no seio familiar.

Estruturalmente, o Cemeei Wakenai é um espaço cercado por ripas de madeira, encontra-se equipado com 80 cadeiras, a metade fornecida pela Semed-AM e outra ofertada por parceiros da escola. Há um quadro branco, fruto de doação, uma mesa de madeira, feita pelos próprios moradores, 


\section{O ENSINO DA LÍNGUA NHEENGATU EM ALDEIAS URBANAS DE MANAUS}

que é utilizada pela educadora e uma biblioteca, que funciona em um container doado e adaptado com livros e espaço de leitura. As aulas ocorrem de segunda a sexta-feira, no período matutino das $08 \mathrm{~h} 30 \mathrm{~min}$ às $10 \mathrm{~h} 30 \mathrm{~min}$, e vespertino, de $14 \mathrm{~h} 30 \mathrm{~min}$ às $16 \mathrm{~h} 30 \mathrm{~min}$. Na escola, há várias placas e cartazes pendurados espalhados com vários desenhos, palavras, frases e até pequenos textos sobre os temas trabalhados nas aulas ou que remetem aos direitos indígenas; geralmente são escritos em língua portuguesa, nheengatu, tikuna e outras, de acordo com algumas línguas étnicas dos alunos. Dessa forma, há todo um empenho desta comunidade indígena citadina para que a os saberes indígenas sejam repassados à nova geração por meio da língua ensinada. Nesta direção,reporta-se no item adiante a descrição desta dinâmica.

\subsection{0 ensino da língua nheengatu em sala de aula - didática e proposta pedagógica}

O ensino da língua nheengatu no Cemeei Wakenai se dá por meio da língua portuguesa, pois, embora haja situações de bilinguismo na escola, principalmente entre alunos da etnia tikuna e tukano, a primeira língua (L1) de todos os estudantes éo português,caracterizando assim, a língua nheengatu como a segunda língua (L2) no foco de aprendizagem na escola como já citado na seção anterior, constituindo-se a língua objeto de reflexão.

Sob a ótica da pedagogia de projetos, estabelecida pela Semed-AM, o Cemeei Wakenai é orientado durante 0 ano letivo a desenvolver projetos que culminem em produção de material didático indígena para a própria escola. Desta maneira, a língua nheengatu é (re)vitalizada por meio do trabalho em conjunto com a professora, alunos e alguns pais dos discentes. Como resultado, já conseguiram produzir uma cartilha de alfabetização, um livro de literatura indígena e um gibi, todos em nheengatu.

Nesse sentido, ao conseguir compor material didático dentro dos planos coletivos de uma comunidade indígena e com participação compartilhada, o Cemeei Wakenai, com esforço, cumpre uma missão considerada demandante do comprometimento com oportunidades de escolhas decisivas nas lutas por seus direitos e interesses, além de colaborar com a construção de currículos que podem ganhar espaço nas escolas indígenas. Essa ação representa importante avanço na escola porque contribui na formação de uma escola autônoma, bilíngue/multilíngue, específica e diferenciada que provoca impactos positivos nos processos de revitalização das línguas indígenas (BANIWA, 2019).

Para o Ministério da Educação (MEC), um dos eixos de sustentação das políticas de educação escolar indígena refere-se à produção de materiais didáticos e paradidáticos amparados na interculturalidade que possibilitem apoio às práticas pedagógicas e curriculares dos professores indígenas na vertente de valorização dos etnoconhecimentos, das formas próprias de constituição e transmissão desses saberes e de contextualização às realidades sociolinguísticas de cada povo 
indígena, ou seja, produções textuais manifestas em variadas linguagens e suportes comunicativos (BRASIL, 2007).

No que tange às práticas linguísticas no CemeeiWakenai, seja na composição dos projetos ou em outras atividades de ensino, as observações feitas durante as visitas técnicas concomitante à entrevista junto à professora, indicaram que a aquisição e a aprendizagem da língua nheengatu se inserem na teoria sociointeracionista, a qual postula que, além dos aspectos cognitivos, psicológicos e biológicos, o ensino e aprendizagem são concebidos socialmente por meio das relações históricas e culturais construídas coletivamente entre os membros de uma dada sociedade, grupo ou comunidade (VYGOTSKY, 1993).Nesta direção,por meio do contato com o outro, os alunos de diversas etnias vivenciam a experiência na língua nheengatu com aulas com temáticas que englobam dança, música, artesanato, desenhos em papel e superfícies diversas, pinturas corporais de diferentes grafismos, contato com a natureza, plantas medicinais, também teatralizam histórias e rituais indígenas e, ainda,exploram os arredores da escola participando de jogos tradicionais indígenas de arco e flecha, corrida do saco, brincadeiras com bola etc.

A dinâmica de acomodação na sala também impulsiona a interação; os alunos são organizados não em filas, porém, em formato de roda de conversa no intuito de estimulara oralidade e a escrita em nheengatu e até em outras línguas indígenas presentes na escola. A ideia é promover uma atmosfera propícia ao contato com tudo o que possa remeter às crenças simbólicas indígenas, suscitando o aprendizado da língua com valor e significados dessas memórias.

Toda essa proatividade de trabalho com a língua nheengatu no Cemeei Wakenai em contexto multiétnico citadino, incita a interculturalidade "enquanto possibilidade de diálogo interativo, convivência e coexistência respeitosa entre diferentes culturas como relações de diálogo colaborativo e solidário e de reciprocidade que permeiam as cosmologias", consoante Baniwa (2019, p. 197), com base nas reflexões de Candau (2000). Com isso, a língua indígena consegue alcançar, ainda conforme Baniwa (p. 81), importante aspecto "sociocósmico de expressão e organização cosmológicas, epistemologias, racionalidades, temporalidades, valores e espiritualidades", ou seja, a língua como elo e condutor funcional de relevância e existência nos alunos, o que permite 0 alcance da vitalidade linguística.Neste mesmo viés, o próprio Referencial Curricular Nacional para as escolas Indígenas (RCNEI, 1998, p. 23) ratifica que "cada experiência cognitiva e afetiva carrega múltiplos significados": sociais, rituais ecosmológicos. Nesse nicho se inserem as vivências com a língua.

Isso implica dizer que o letramento ${ }^{2}$ na educação escolar indígena possui significação diferenciada da educação ocidental, calcada, muitas vezes, na valorização e domínio elevado da escrita de letras e números. Nos povos indígenas, o letramento é fortemente marcado pela presença de símbolos gráficos não alfabéticos, assim, as formas, traços, cores, esculpidos em seus corpos, 


\section{O ENSINO DA LÍNGUA NHEENGATU EM ALDEIAS URBANAS DE MANAUS}

transcendem o olhar de "simples adornos corporais, mas registram rituais de passagens, indicam o clã a que 0 indígena pertence e muitas outras informações [...] o que confere grande complexidade e requer um conhecimento específico" (SIMAS; PEREIRA, 2012, p.58), isto é, denotam outras maneiras de comunicação e percepção, tão relevantes quanto as atribuídas à escrita alfabética não indígena, salienta a autora.

Portanto, as práticas linguísticas em nheengatu no Cemeei Wakenai são experiências que estão galgando os degraus do letramento indígena, na medida em que não só a leitura e escrita de palavras e enunciados fazem parte desse processo,como também os símbolos e demais gêneros discursivos carregados de saberes culturais apreendidos nas experiências partilhadas que durante as aulas ganham sentido e relevância nas práticas sociais dos alunos, dentro e fora da comunidade.Contextos como esses apresentam inúmeros desafios, mas também exemplos de superação.

\subsection{Desafios e Avanços no cotidiano do Cemeei Wakenai}

Os desafios e os avanços na trajetória etnoeducacional no Cemeei Wakenai são norteados por fatores internos e externos que refletem na evolução do aprendizado. O primeiro fator diz respeito ao interesse e à organização da comunidade em fortalecer seus aspectos linguísticos e culturais por meio da educação escolar indígena. Essa mobilização, conforme percebido durante esta pesquisa, tem sido alcançada. 0 segundo fator, por sua vez, depende do apoio de políticas públicas para continuar levando seus projetos adiante.

Os principais agravantes, interferentes no aprendizado dos alunos, são os problemas estruturais do próprio espaço físico do referido Cemeei, dentre eles: banheiro em estado precário, um bebedouro sem manutenção, um refeitório sem os devidos cuidados de higiene, a própria falta de materiais escolares, como pincéis, apagadores, papéis, lápis de escrever e pintar e, ainda, falta de didático na língua nheengatu ou até mesmo em outras línguas. Os itens elucidados são considerados essenciais em um ambiente escolar, pois fazem parte da contribuição de uma educação exitosa, independentemente do tipo de ensino, conforme pontua a professora, em uma de nossas entrevistas:

Eu percebo que a falta de recursos e estrutura prejudica o aprendizado deles, que às vezes precisam parar as atividades porque precisam ir ao banheiro ou beber água ou ainda quando pedem algum material para fazer alguma atividade de uma simples pintura e nós não temos. Mesmo assim vamos dando um jeito. (PROFESSORA CLÁUDIA, 2018) 
Ou seja, esse centro educacional é bastante carente tanto em termos estruturais quanto em termos de materiais didático-pedagógicos. Avaliando a questão, a situação deste Cemeei esbarra na negligência das políticas públicas municipal e estadual, que não concebem a educação voltada aos indígenas como uma prioridade. A realidade do Cemeei Wakenai pode servir de parâmetro quando se reflete sobre a real condição de vários outros centros de educação escolar indígena alocados na cidade de Manaus. Para Grupioni (2000, p. 143), "a impressão que se tem é que a educação escolar indígena caminha a passos lentos: avança em direção a algumas conquistas, mas inúmeros obstáculos se apresentam a cada momento". Segundo este autor, ainda não se estruturou um sistema que atenda às necessidades educacionais dos povos indígenas, priorizando seus interesses, respeitando seus modos de vida, resguardando o papel das comunidades na definição e no funcionamento do tipo de educação que desejam.

Porém, em meio às dificuldades, os avanços são percebidos. 0 aprendizado linguístico, através das atividades elencadas na seção anterior, tem acontecido, notadamente, pelo interesse e participação dos alunos.Eles já conseguem contextualizar pequenos diálogos e símbolos em língua nheengatu, redescobrindo as tradições indígenas. 0 proceder pedagógico, longe da formalidade padrão de uma sala de aula tradicional, é oferecido aos alunos o aprender da língua nativa de maneira atrativa e socializada,o que se torna uma singularidade positiva em um espaço de saberes tradicionais. Logo, a língua indígena transita, se fortalece e ocupa lugar de destaque no espaço de aprender da comunidade. Em suma, como afirma Teixeira (1995), a língua é também a chave de valor inestimável que permite perceber o conhecimento acumulado no universo cultural de um povo.

Outro progresso bastante positivo é desencadeado com o ensino linguístico no Cemeei Wakenai. A escola é convidada para diversos eventos indígenas e não indígenas de cunho formal e informal na capital, apresentando teatro, danças, músicas e performances diversas feitas primeiramente em língua nheengatu, depois português e, em algumas ocasiões, na língua tikuna, que também é bastante falada no Parque das Tribos, logo, dispõe de destaque nas atividades e nas apresentações da escola.Nas exibições fica perceptível que o conhecimento brotado diariamente no Cemeei funciona como um instrumento de empoderamento com a língua ocupando lugar privilegiado na militância das causas indígenas.

Com efeito, apesar dos prejuízos, historicamente acarretados pelas escolas nas sociedades indígenas, em tempos mais atuais, essa população aprendeu a conviver com ela, demandando-a e recriando-a para proveito próprio. Nas ponderações de Bergamaschi e Medeiros (2010), observa-se no cotidiano das escolas nas aldeias e nos centros urbanos, práticas que buscam na memória, na tradição, nos saberes ancestrais e no ensino de histórias a afirmação de suas identidades étnicas, transformando esses espaços e as práticas que neles se desenvolvem em fortes 
instrumentos de reivindicação de seus direitos, sobretudo no que diz respeito à legalização de seus territórios, sendo esta uma das maiores lutas indígenas da atualidade.

Ao colocar em voga o conjunto de aspirações supracitadas no âmago do seu local de ensino, a escola indígena é tida como um espaço síncrono conscientizador de diálogos atravessadores de vários processos, dentre eles a história, a política, o social e a interculturalidade com o desígnio de avultar seus azos de liberdade, cada expectação tem um propósito frente a sociedade não indígena, conforme indica Fernandes (2018, p. 67-68):

\footnotetext{
Como processo histórico, ela se constitui como importante instituição que, ao longo da história do contato, foi utilizada para diferentes finalidades que vão desde a evangelização dos povos indígenas à cooptação para o trabalho compulsório.Como movimento político ela se constitui como importante mecanismo para se pensar as estratégias utilizadas pelos povos indígenas e suas conquistas. Como lugar de sociabilidades, tais escolas se constituem, no seio das aldeias, como importantes espaços onde diferentes sujeitos sociais se reúnem e refletem sobre diferentes conhecimentos. Como espaço intercultural ela se apresenta como oportunidade ao diálogo entre diferentes culturas e possibilidade de construção de novos saberes.
}

As motilidades elencadas indicam que a escola indígena é um espaço de múltiplas funções pautadas nos objetivos das conquistas que os indígenas almejam e sonham ter. 0 referido autor aponta ainda que nesse espaço, o fazer pedagógico é um constructo de ferramentas diferenciadas no processo educacional, de modo que os conhecimentos apreendidos coletivamente impulsionam seus partícipes a serem protagonistas indígenas no âmbito de uma cidadania que seja demarcada pelos direitos civis concomitante ao reconhecimento e inclusão da diversidade e da diferença.

Portanto, nessa perspectiva, a língua nheengatu atrelada aos saberes tradicionais, no Cemeei Wakenai, e, por conseguinte, na própria comunidade, representam formas próprias de comunicação. Esta, por conseguinte, ganha novos aspectos na visão de mundo nas reafirmações identitárias e respeito étnico por parte dessa nova geração.

\subsection{O significado do ensino da língua nheengatu para a nova geração no Parque das Tribos}

Percebeu-se durante as visitas técnicas que, para a nova geração do Parque das Tribos, 0 contato e apreensão dos significados trazidos pela língua nheengatu a esse público, equivale valorizar e ter orgulho de sua história, de sua origem, ou seja, é consolidar o sentimento de pertencimento tonificando a identidade indígena. "Eu me sinto satisfeita porque a gente vê que eles tão lendo ali né?!, os que têm celular vão lá bate foto do que se escreve ou se ensina aqui, isso é ótimo porque demonstra o vínculo deles com os nossos saberes", afirma a professora Cláudia Baré, que junto com 
os alunos criou uma página na rede social Facebook do Cemeei ,onde compartilha fotos e vídeos das atividades da escola e participação dos alunos em programações tanto no Parque das Tribos quanto em outros eventos na cidade de Manaus. Sobre isso, a professora Cláudia complementa: "Eles dançam, atuam, cantam e falam com amor, pleiteando as nossas causas em todas as apresentações que fazemos na cidade, utilizando todo tipo de equipamento possível, tradicional e tecnológico".

A fala da professora se coaduna com o que foi observado - a língua e saberes sendo (re)vitalizados em um formato consoante com as demandas atuais de uma vida urbana, ou seja, as possibilidades quanto ao uso das tecnologias da informação têm gerado novos arranjos culturais e reconfigurações identitárias nas populações indígenas. Sobre esse assunto, posiciona-se Maher (2016) ao afirmar que as tecnologias produzidas pelos não indígenas estão sendo assimiladas pelos indígenas e utilizadas como instrumentos de suas ações e de expressão de suas identidades culturais particulares. "Mais recentemente, vimos assistindo, também à apropriação de novas tecnologias digitais por esses povos para registrarem suas manifestações culturais", sustenta a autora (MAHER, 2016, p. $65)$.

Se reportando a Bakhtin (1992), Baniwa (2019), nessa mesma linha de pensamento, concorda que as línguas e as culturas indígenas acompanham as mudanças sociais, são receptivas às atualizações em face das inovações, descobertas, invenções que vão transformando o mundo e 0 pensamento dos distintos grupos humanos. $O$ autor indígena acredita que esse acompanhamento de atualização linguística deve ser equilibrado para não correr o risco de se perder o código pela influência de outros, porém, é uma maneira de favorecer a língua com vitalidade, dinâmica e relevância nas práticas do cotidiano, as quais estão, cada vez mais, imbricadas aos aportes tecnológicos.

Diante do exposto, pode-se inferir que ao vivenciar a essência da língua nheengatu e da cultura no contexto urbano, a nova geração dos alunos no Parque das Tribos constrói vínculos com os elementos associados à vida grupal e comunitária. Os alunos buscam reproduzir as tradições dos antepassados no contexto da cidade e fazem isso, não a partir da negação do contato de suas histórias, mas a partir de uma experimentação com as alteridades advindas da era globalizada e tecnológica. Em espaço multiétnico reafirmam suas identidades fundamentadas em princípios culturais, recorrendo à educação escolar indígena como alternativa de empoderamento para o enfrentamento nas diligências das mudanças e transformações sociais benéficas para as populações indígenas.

\section{CONSIDERAÇÕES FINAIS}

Objetivou-se com este estudo avaliar a forma como vem se desenvolvendo o ensino da língua nheengatu no Centro Municipal de Educação Escolar Indígena Uka Umbuesara Wakenai 


\section{O ENSINO DA LÍNGUA NHEENGATU EM ALDEIAS URBANAS DE MANAUS}

Anumarehit, na cidade de Manaus, estabelecendo para isso algumas metas, dentre as quais: destacar a didática e a proposta pedagógica utilizada no local; pontuar as dificuldades e conquistas no percurso de ensino e aprendizagem etnolinguística dessa escola e, por fim, evidenciar o que o aprendizado da língua nheengatu tem significado para a nova geração de indígenas enquanto residentes de uma aldeia em contexto urbano.

Nesse cenário, a educação escolar indígena, enquanto alternativa para a superação das perdas significativas das populações indígenas que vivem nas grandes cidades, vem se revelando como uma estratégia positiva na luta pela valorização da língua étnica, tida como elemento da cultura que enaltece as tradições, impulsiona a afirmação identitária de cada grupo indígena, conjuntamente com outros componentes culturais como a terra, a ancestralidade, os rituais, as pinturas e as cerimônias.

Transferindo a situação para realidade do Cemeei Wakenai, na cidade de Manaus, com base nas observações participantes e nas informações coletadas na entrevista com a professora, 0 ensino da língua nheengatu se desenvolve com os alunos de variadas etnias. Nessa troca de experiências linguística em sala de aula, cada um vai aprendendo com o outro e por meio de teatro, danças, música, artesanato, grafismos, pinturas corporais e desenhos, símbolos que junto à leitura e à escrita de palavras tem fornecido subsídios que permitem o letramento indígena.

No que diz respeito à didática aplicada na escola, esta se insere, como já citado, na teoria Vygotskiana sociointeracionista. Os temas trabalhados em sala de aula são variados e dependem do objetivo a ser alcançado. Com relação à proposta pedagógica, esta ocorre sob a orientação da Gerência de Educação Escolar Indígena da Semed-AM e é pautada na pedagogia de projetos para que,no decorrer do ano letivo,o Cemeei Wakenai elabore material didático de educação indígena para o próprio centro.

Concernente às demandas e progressos no cotidiano do Cemeei Wakenai, estes são marcados por anseios e superações. Enfrentam problemas com a estrutura física do local e de uma assistência mais perene por parte da secretaria que a assessora, tais como: recursos didáticos e pedagógicos que viabilizem melhorias no ensino.

Por outro lado, os pontos positivos mostram que o letramento indígena paulatinamente ganha consistência neste Cemeei; os alunos, mesmo residentes em perímetro urbano, imersos na cultura não indígena, estão aprendendo a falar,escrever na língua nheengatu e a lidar com a leitura e funcionalidade de alguns símbolos étnicos na comunidade. Observou-se, ainda, que tanto a docente quanto os discentes não encaram a fertilidade dos elementos tecnológicos, musicais e outras concepções dos não indígenas, tão contraditórias ao estilo tradicional de vida indígena, como razão de distanciamento ou impedimento de interesse pelos saberes indígenas; pelo contrário, adaptam esses 
mecanismos a favor de um aprendizado que os motive a reafirmarem suas identidades e ressignificarem suas práticas sociais dentro e fora da comunidade.

Finalmente, quanto ao significado que a nova geração de alunos indígenas do Parque das Tribos tem concebido a partir do contato mais íntimo no aprendizado da língua nheengatu, é de valorização e retomada de suas histórias, origens e costumes. Também se percebe neles que, as práticas linguísticas em nheengatu e até em outras que, devido ao contexto multiétnico estão presentes na sala de aula, impulsionam um sentimento de pertencimento e reafirmação identitária, unindo-se às demais vozes indígenas da comunidade para reivindicarem perante as políticas públicas 0 cumprimento dos seus direitos indígenas e de cidadãos brasileiros.

Assim, baseado na experiência obtida com o Cemeei Wakenai, pode-se inferir que 0 ensino da língua nheengatu, assim como de outras para novas gerações de indígenas residentes em aldeias urbanas em Manaus, se desenvolve de forma singular, respeitando os preceitos da educação escolar indígena e contando com o empenho de seus professores, interesse e entusiasmo dos alunos para que suas práticas sociais adquiram função não só de sentido, mas, também,de empoderamento junto às causas indígenas na luta da comunidade por melhores condições de vida na cidade.

\section{REFERÊNCIAS}

ATHIAS, Renato. A noção de identidade étnica na antropologia brasileira: de Roquette Pinto à Roberto Cardoso de Oliveira. 2 ed.Recife: Editora Universitária da UFPE, 2007.

BANIWA, Gersem. Educação escolar indígena no século XXI: encantos e desencantos. Rio de Janeiro: Mórula, Laced, 2019.

BRASIL. Referencial Curricular Nacional para a Educação Indígena (RCNEI). Ministério da Educação e do Desporto. Secretaria de Educação Fundamental. Brasília: MEC/SEF, 1998.

BRASIL. Ministério da Educação. Educação Escolar Indígena: diversidade sociocultural indígena ressignificando a escola. Brasília: Cadernos Secad, MEC, 2007.

BERGAMASCHI, Maria Aparecida; MEDEIROS, Juliana Schneider. História, memória e tradição na educação escolar indígena: o caso de uma escola Kaingang. Revista Brasileira de História. São Paulo, v. 30, n. 60, p. 55-75, 2010. Disponível em: https://www.scielo.br/pdf/rbh/v30n60/a04v3060.pdf. Acesso em: 25 abr. 2020.

BROSTOLIN, Marta Regina. Da política linguística à língua indígena na escola. Revista Tellus, ano 3 , n. 4, abril, 2003. Disponível em:

http://www.gpec.ucdb.br/projetos/tellus/index.php/tellus/article/download/60/63. Acesso em: 25 abr.2020.

CALVET, Louis-Jean. Sociolinguística: uma introdução crítica. São Paulo: Parábola, 2002. 
CANDAU, Vera. Interculturalidade e educação escolar. In: CANDAU, V. (org.).Reinventar a escola. Petrópolis, 2000.

COHN, Clarice. Culturas em transformação: os índios e a civilização. Revista São Paulo em Perspectiva, v. 15, n. 2, 2001. Disponível em: www.scielo.br/scielo. Acesso em: 18 set. 2017.

COPIME - Coordenação dos Povos Indígenas de Manaus e Entorno. Disponível em https://www.indigenasemcidades.com/sites-1. Acesso em: 4 abr. 2020.

COUTO. Hildo Honório do. Linguística, Ecologia e Ecolinguística: contato de línguas. 2 ed. São Paulo: Contexto, 2012.

FERNANDES, Fernando Roque. Protagonismo indígena no tempo presente.Amazônida (Ufam),v.3, p.65, 2018. Disponível em: https://periódicos.ufam.edu.br/index.php/amazonida. Acesso em: 13 maio 2020.

GRUPIONI, Luís Donisete Benzi. A Educação Escolar Indígena no Brasil: a passos lentos.In: RICARDO, Carlos Alberto (org.). Povos indígenas no Brasil. São Paulo: Instituto Socioambiental, 2000.

KLEIMAN, A. B. Preciso ensinar o letramento? Não basta ensinar a ler e escrever? Campinas: UNICAMP: Cefiel \& MEC: Secretaria de Ensino Fundamental, 2005.

LUCIANO, Gersem dos Santos. O Índio Brasileiro: o que você precisa saber sobre os povos indígenas no Brasil de hoje. Brasília: Ministério da Educação, Secretaria de Educação Continuada, Alfabetização e Diversidade; Laced/Museu Nacional, 2006.

MAHER, Terezinha Machado. Sendo índio na cidade: mobilidade, repertório linguístico e tecnologias. Revista da Anpoll, n. 40, Florianópolis, janeiro/junho de 2016, p. 58-69. Disponível em: https://revistadaanpoll.emnuvens.com.br. Acesso em: 21 out. 2017.

MINAYO, Maria Cecilia de Souza (org.); DESLANDES, Suely Ferreira; GOMES, Romeu. Pesquisa Social: teoria, método e criatividade. 33. ed. Petrópolis, RJ: Vozes, 2013.

MUSTAFA, Amanda Ramos. As línguas étnicas no Parque das Tribos em Manaus: Um estudo etnolinguístico nos espaços culturais indígenas Uka Umbuesara Wakenai Anumarehit e Kokama 2018. Dissertação (Mestrado em Letras e Artes). Universidade do Estado do Amazonas - UEA, 2018.

PEREIRA, José Carlos Matos. Indígenas na metrópole: lutas multiétnicas e identidade coletiva na cidade de Manaus (AM) 2016. (Apresentação de Trabalho/Conferência ou palestra). Disponível em: https://portal.ufrrj.br/wp-content/uploads/2018/06/Os-ind\%C3\%ADgenas-na-cidade-de-ManausVers\%C3\%A3o-final.pdf. Acesso em: 4 abr. 2020.

POVOS INDÍGENAS NO BRASIL. Página categoria "Povos indígenas no Amazonas". https://pib.socioambiental.org/pt/Categoria:Povos_ind\%C3\%ADgenas_no_Amazonas. Acesso em: 16 maio 2020.

RAJAGOPALAN, K. O conceito de identidade em linguística: é chegada a hora para uma reconsideração radical? In: SIGNORINI, I. (org.) Língua(gem) e identidade: elementos para uma discussão no campo aplicado. Campinas: Mercado das Letras, 1998, p. 21-45. 
RODRIGUES, AryonDall'Igna. Línguas indígenas brasileiras ameaçadas de extinção (Laboratório de Línguas Indígenas, Universidade de Brasília, agosto de 2016). Disponível em: http://2014.revistaintercambio.net.br/24h/pessoa/temp/?file=anexo,1,117,122,122.L\%EDnguas\%20ind\% EDgenas \%20brasileiras:\%20pesquisa\%20e\%20documenta\%E7\%E30\%20ling\%FC\%EDstisca. Acesso em: 28 nov. 2020.

SASTRE, Patricia Martínez. Índios urbanos: buscando as raízes longe da natureza. Publicado em outubro de 2015. Disponível em: https://brasil.elpais.com/brasil. Acesso em: 12 out. 2017

SIMAS, H. C. P.; PEREIRA, R.C.M . Letramento Indígena Potiguara. Manaus: Valer, 2012.

STREET, B. Perspectivas interculturais sobre o letramento. Revista Filologia eLinguística Portuguesa. São Paulo, v. 8, 2006.

TEIXEIRA, Raquel F. A. As Línguas Indígenas no Brasil. In LOPES DA SILVA, Aracy \& GRUPIONI, Luís Donisete Benzi (orgs.). A Temática Indígena na Escola.

Brasília:MEC/Mari/Unesco,1995.Disponívelem: http://www.pineb.ffch.ufba.br. Acesso em 13 dez. 2016.

TRIVIÑOS, Augusto Nibaldo Silva. Introdução à pesquisa em ciências sociais: a pesquisa qualitativa em educação. São Paulo: Atlas, 2013.

VYGOTSKY, Lev S. Pensamento e linguagem. São Paulo: Martins Fontes, 1993.

\section{Notas}

${ }^{1}$ Número impreciso, não se sabe ao certo o número exato. O IBGE (2010) aponta cerca de 274, a literatura em trabalhos científicos como de Luciano (2006); Rodrigues (2016) e Baniwa (2019) cogitam entre 180 e 210 línguas.

2 Coadunamos com as premissas de Kleiman (2005) e Street (2006) sobre o conceito do termo letramento. Para Kleiman (2003), o letramento é situado no sentido atribuído às práticas de valores e culturais em uma dada sociedade. Já Street faz alusão ao termo "práticas de letramento" como fator ideológico porque independentemente do tipo de leitura ou escrita aprendidos, há sempre uma contextualização dessas práticas, as quais se associam a identidade humana com expectativas sociais de comportamento e papéis a desempenhar. 